\title{
Effect of naproxen on proliferation and differentiation of primary cell cultures isolated from human cartilage tissue
}

\author{
NUMAN KARAARSLAN ${ }^{1}$, AHMET GURAY BATMAZ ${ }^{2}$, IBRAHIM YILMAZ ${ }^{3}$, HANEFI OZBEK ${ }^{3}$, \\ TEZCAN CALISKAN $^{1}$, DUYGU YASAR SIRIN ${ }^{4}$, NECATI KAPLAN $^{5}$, KADIR OZNAM $^{6}$ and OZKAN ATES $^{7}$ \\ ${ }^{1}$ Department of Neurosurgery, School of Medicine, Namik Kemal University, Tekirdag 59100; \\ ${ }^{2}$ Department of Orthopaedics and Traumatology, Atasehir Hospital, Istanbul 34384; ${ }^{3}$ Department of Medical Pharmacology, \\ School of Medicine, Istanbul Medipol University, Istanbul 34810; ${ }^{4}$ Department of Molecular Biology and Genetics, \\ Faculty of Arts and Sciences, Namik Kemal University; ${ }^{5}$ Department of Neurosurgery, Istanbul Rumeli University, \\ Corlu Reyap Hospital, Tekirdag 59100; ${ }^{6}$ Department of Orthopaedics and Traumatology, School of Medicine, \\ Istanbul Medipol University, Istanbul 34214; ${ }^{7}$ Department of Neurosurgery, Istanbul Esenyurt University, \\ Esencan Hospital, Istanbul 34510, Turkey
}

Received January 23, 2018; Accepted May 11, 2018

DOI: $10.3892 /$ etm.2018.6351

\begin{abstract}
Non-steroidal anti-inflammatory drugs (NSAIDs) that are applied through oral, injectable or topical routes have been widely used in painful and inflammatory musculoskeletal diseases. The current study aimed to determine whether naproxen, an aryl acetic acid derivative with analgesic and anti-inflammatory effects, has a toxic effect on human chondrocytes. Samples containing monolayer primary chondrocyte cultures were prepared following resection from osteochondral tissues obtained from patients with gonarthrosis. Cell viability, toxicity and proliferation and levels of stage-specific embryonic antigen-1, a precursor to human prechondrocytes, were evaluated spectrophotometrically. The results from the untreated control group were compared with those of the study groups, where naproxen was administered in varying doses (1-1,000 $\mu \mathrm{M})$. Surface morphologies of the cells were compared using inverted light and environmental scanning electron microscopy. Treatment groups were compared by analysis of variance with Tukey's honest difference post hoc test. $\mathrm{P}<0.01$ was considered to indicate a statistically significant difference. The research revealed significant changes to proliferation and differentiation of chondrocytes in all treatment groups $(\mathrm{P}<0.01)$. Naproxen was demonstrated to suppress chondrocyte proliferation and differentiation, which may be an important factor to consider when prescribing this medication to patients.
\end{abstract}

Correspondence to: Dr Numan Karaarslan, Department of Neurosurgery, School of Medicine, Namik Kemal University, 1-14 Campus Street, Tekirdag 59100, Turkey

E-mail: numikara@yahoo.com

Key words: aryl acetic acid, chondrotoxicity, proliferation, stage-specific embryonic antigen-1

\section{Introduction}

To stabilize the anabolic and catabolic cycles in cartilage tissue, it is important that acid and alkaline levels remain constant. Decreased pH levels, leading to an acidic cartilage environment, results in tissue degeneration $(1,2)$. Healthy cartilage tissues with alkali $\mathrm{pH}$ values reach acidic $\mathrm{pH}$ values at various levels during inflammation (3). Non-steroidal anti-inflammatory drugs (NSAIDs) are frequently prescribed to patients with acute pain resulting from musculoskeletal inflammation (3). As a result of this treatment, $\mathrm{pH}$ values in cartilage decrease from alkali to acidic values, which may result in pain, tissue damage and potential loss of function (4). The majority of frequently prescribed analgesic and anti-inflammatory drugs contain acid functional groups and are capable of binding to plasma proteins (3). Inflamed tissues exhibit an acidic $\mathrm{pH}$ and display increased permeability, promoted by accumulation of NSAIDs in these areas (5). As the $\mathrm{pH}$ decreases, the oil-solvable ionized part increases, the relationship with the lipid structure of the cell membranes and the effect of the drugs increases (6).

Naproxen is an NSAID of the propionic acid class (7). Upon literature examination, several studies were identified which assessed the various side effects and/or adverse events of naproxen (8,9). However, in a study by Gumustas et al (10), it was expressed that no other such research had been performed, except for a drug named flurbiprofen, which is a member of the NSAID phenyl alkanoic acid family $(7,11,12)$. Thus, the present study aimed to investigate the effect of Naproxen on chondrocyte viability and proliferation, as it is an agent that creates a more acidic environment by lowering the $\mathrm{pH}$ value. In addition, the present study assessed the effect of naproxen administration on the expression of stage-specific embryonic antigen-1 (SSEA-1), a prechondrocytic marker.

The prechondrocytic stage-specific embryonic antigen-1 (SSEA-1) marker was used to analyse whether cells in primary chondrocyte cultures undergo differentiation or maintain their 
undifferentiated structure and if they undergo stimulation or inhibition (13). A previous study has demonstrated that during human mesenchymal stem cell contain embryonic stem cell differentiation; the SSEA-1 protein component is upregulated (13). However, in cells that do not undergo differentiation, the SSEA-1 marker is downregulated (13). In previous studies that did not prepare cell lysates, the characterization of cells in chondrocyte cultures was assessed by detecting the increase or decrease in SSEA-1 in cultured cells. Thus, the presented study utilized the SSEA-1 marker for molecular analysis (13).

\section{Materials and methods}

Selection criteria for tissue samples. The present study analyzed osteochondral tissues obtained from 15 patients diagnosed with gonarthrosis who underwent total knee arthroplasty surgery. Tissues from 4 patients who received NSAIDs, disease-modifying antirheumatic drugs $(n=3)$ and biological agents $(n=2)$ within the last month were excluded from the present study and the remaining 6 patients (3 males and 3 females; age range, 59-76 years; mean age, 66 years) were included. These patients underwent surgery at the Orthopaedics and Traumatology Departmen, Medipol University Medical Faculty (Istanbul, Turkey) between November 2016 and December 2017. Research was conducted with the approval of The Ethics Committee of Istanbul Medipol University School of Medicine (Istanbul, Turkey; ethical permission no. 10840098-604.01.01-E.5734). Written informed consent was obtained from all patients prior to inclusion.

Materials. Collagenase type II (Clostridium histolycum; $1 \mathrm{mg} / \mathrm{ml}$ ) and Hank's balanced salt solution (HBSS) were obtained from Thermo Fisher Scientific, Inc. (Waltham, MA, USA). Fetal bovine serum (cat. no. 12103C), Dulbecco's modified Eagle's medium (DMEM; 1,000 mg/l glucose; cat. no. D5796), L-glutamine (cat. no. G3126), insulin, transferrin, sodium selenite media supplement (cat. no. I1884) and dimethyl sulfoxide (DMSO) were all obtained from Sigma-Aldrich (Merck KGaA, Darmstadt, Germany). An MTT kit (Vybrant MTT Cell Proliferation assay; cat. no. V-13154) was purchased from Cell Biolabs, Inc. (San Diego, CA, USA). The SSEA-1 Human Mesenchymal Stem Cell Characterization kit (cat. no. K36094-21A) was obtained from Celprogen, Inc. (Torrance, CA, USA). Naproxen was supplied by Abdi Ibrahim Pharmaceuticals (Istanbul, Turkey). Nüve Laboratory \& Sterilisation Technology (Ankara, Turkey) supplied the laminar flow cabinet (cat. no. NF-800 R) and incubator (cat. no. 06750). Inverted light microscopy was performed with an Olympus microscope (cat. no. CKX41; Olympus Soft Imaging Solutions $\mathrm{GmbH}$, Münster, Germany) and images were evaluated using the software supplied by the manufacturer. An ELISA reader was obtained from Mindray Bio-Medical Electronics Co., Ltd. (MR 96A; Shenzhen, China). The environmental scanning electron microscope (ESEM) was a FEI Quanta 250 field emission gun (FEG; Thermo Fisher Scientific, Inc.).

Study design. Human primary chondrocyte cultures without naproxen were used as controls (Group I). The study groups were then divided into Groups II-VII, which were treated with increasing doses $(1,10,100,250,500$ and $1,000 \mu \mathrm{M}$, respectively) of naproxen. Samples from all groups were tested and compared using spectrophotometric assays 24,48 and $72 \mathrm{~h}$ following naproxen treatment at $37^{\circ} \mathrm{C}$ in a humidified $\mathrm{CO}_{2}$ incubator. MTT cell viability, toxicity, proliferation and SSEA-1 protein levels were the subsequently assessed. The surface morphology of samples was then compared using an inverted light microscope (magnification, x20) and ESEM. Researchers who examined results were blind to the drugs and dosages utilized in each group. Experiments were performed at least 3 times.

Isolation and culturing of primary human chondrocytes and preparation and application of naproxen. Osteochondral tissue was obtained from 15 patients diagnosed with gonarthrosis who underwent total knee arthroplasty surgery at Istanbul Medipol University School of Medicine, Department of Orthopaedic and Traumatology (Istanbul, Turkey) $(n=15)$. Tissues from patients who had used NSAIDs $(n=4)$, disease-modifying antirheumatic drugs $(n=3)$ and biological agents $(n=2)$ within the last month were excluded The tissues of 6 patients diagnosed with stage IV Gonarthrosis were used to establish cell cultures. The Kellgren-Lawrence protocol was used to determine the stage of loss of cartilage to consider these patients for surgery (14). Resected tissues were transferred to the laboratory for culture in Falcon tubes containing Penicillin-Streptomycin according under previously described transfer conditions (1). Following the separation of resected osteochondral tissue from chondral tissue using a rounger, the undamaged and intact chondral regions were used for cell cultures.

Tissue samples were transferred to tubes following their removal from bone and collagenase type II $(200 \mathrm{u} / \mathrm{ml})$, dissolved in HBSS, was added. Tissue samples were incubated for $16 \mathrm{~h}$ at $37^{\circ} \mathrm{C}$ in a $\mathrm{CO}_{2}$ incubator. Tissue samples were then centrifuged at $4^{\circ} \mathrm{C}$ at $890 \mathrm{x}$ g for $10 \mathrm{~min}$ to discard collagenase. Sedimented cartilage tissue pellets were resuspended in culture medium (DMEM) to obtain primary cultures and medium was replaced every 2 days.

Primary cultures were established and multiplied (to make a total of 6 primary cultures) with samples taken from each patient. Passages were then performed to create 7 experimental groups from these primary cultures. During passage, at least 3 cultures were established for each experimental group and technically reprocessed for all applied methods. In summary, cells were replicated for morphological evaluation as follows: 7x3 petri plates, 7x3 for MTT and 7x3 for SSEA-1.

When primary cultures reached a confluency of $\sim 90 \%$, cells were detached using trypsinization and a scraper, and stained with trypan blue (cat. no. T8154; Sigma-Aldrich; Merck KGaA). As viable cells do not absorb trypan blue, the solution was added to the cell suspension in a ratio of 1:4, placed on a Thoma slide (Paul Marienfeld GmbH \& Co. $\mathrm{KG}$, Lauda-Königshofen, Germany) at $37^{\circ} \mathrm{C}$ for $12 \mathrm{~min}$ and counted using an inverted microscope (magnification, x10) as previously described (1). Viable chondrocyte cells were then plated in 96-well plates at a density of $1.5 \times 10^{4}$ cells/well, in 24 -well plates at a density of $3.3 \times 10^{4}$ cells/well and in $10 \mathrm{~mm}$ petri dishes at a density of $4.4 \times 10^{6}$ cells/dish.

Naproxen $(550 \mathrm{mg}$ ) was aseptically dissolved in DMSO (3.65 $\mu \mathrm{M} / \mathrm{ml})$ to produce a main stock concentration of 
Table I. Agents, commercial stock solution concentrations and final concentrations.

\begin{tabular}{lccc}
\hline Pharmacological agent & Commercial stock solution $(\mathrm{mg} / \mathrm{ml})$ & Final concentration $(\mu \mathrm{M} / \mathrm{ml})$ & Groups \\
\hline Untreated control & $\mathrm{n} / \mathrm{a}$ & $\mathrm{n} / \mathrm{a}$ & Group I \\
Naproxen & 100 & 1 & Group II \\
Naproxen & 100 & 10 & Group III \\
Naproxen & 100 & 100 & Group IV \\
Naproxen & 100 & 250 & Group V \\
Naproxen & 100 & 500 & Group VI \\
Naproxen & 100 & 1000 & Group VII \\
\hline
\end{tabular}

$100 \mathrm{mg} / \mathrm{ml}$. This was then further diluted to obtain 1,000 , $500,250,100,10$, and $1 \mu \mathrm{M} / \mathrm{ml}$ treatment solutions used with culture medium. Group I was selected as the non-drug control group and Group II-VI were treated with naproxen for 24, 48 and $72 \mathrm{~h}$ (Table I).

To perform MTT viability and SSEA-1 analyses, cells from each group were proliferated and subgroups were formed and treated with the aforementioned doses of naproxen. Drug solutions were delivered to the researchers in lightproof bottles to perform the analyses. Primary cultures were established and multiplied with samples obtained from each patient (6 primary cultures). Passages were then performed to form 7 experimental groups from these primary cultures. When these passages were performed, 3 cultures were established for each experimental group and technically reprocessed in these cultures. At least three of the cultures established for the reprocessing technique were tested for each applied method. Cells were replicated for morphological evaluation as $7 \times 3$ petri plates, 7x3 for MTT and 7x3 for SSEA-1 (24, 48 and 72 h).

Inverted light microscopy. Images of cell organizations belonging to cartilaginous tissues were recorded at magnification, $x 4, x 10, x 20$ and $x 40$ with phase-contrast confocal microscopy prior to and following drug application. The images were recorded using the Olympus cell soft imaging system (Olympus Soft Imaging Solutions GmbH, Münster, Germany).

ESEM analysis. ESEM analysis was performed for information about surface topography and compositions of all experimental samples. Images of extracellular matrix (ECM) in the cultural environments and the structural characteristic of the cells were then scanned. The culture medium was then removed from plates. A mixture of cacodylate (cat. no. C0250) and glutaraldehyde (cat. no. G5882; both Sigma-Aldrich; Merck KGaA) were used for fixation at room temperature for $2 \mathrm{~h}$. The culture medium removed from the wells and cells were incubated with cacodylate $(0.2 \mathrm{M}) /$ glutaraldehyde $(2.5 \%)$ buffer at room temperature for $2 \mathrm{~h}$. Samples were washed three times using cacodylate $(0.2 \mathrm{M})$ buffer prior to analysis.

FEG ion pumps were used to generate high vacuum. Images were recorded at 219-226 $\mathrm{Pa}$ in ESEM vacuum mode with magnification, $x 5,000$. Resolution depth horizontal field width was $82.9 \mu \mathrm{m}$ operating voltage was $5.00 \mathrm{kV}$ and working distance was 7.3-10.3 $\mathrm{mm}$.
MTT-ELISA analyses. According to the protocols of previous studies, viability tests were performed using an MTT kit (1,5,6,10,13,15-20). Cartilage cells were analysed at $0,24,48$ and $72 \mathrm{~h}$ prior to and following naproxen administration. To achieve this, medium was removed from cells prior to incubation. The fresh MTT stock solution was then prepared (containing MTT tetrazolium (2 $\mathrm{mM})$ diluted with DMEM. Hydrochloric acid $(0.01 \mathrm{M})$ and SDS $(0.1 \mathrm{~g} / \mathrm{ml})$ were added to wells, followed by $100 \mu \mathrm{l}$ MTT stock solution. Samples were incubated for $150 \mathrm{~min}$ in the dark at $37^{\circ} \mathrm{C}$. Samples $(25 \mu 1)$ were removed, DMSO $(50 \mu 1)$ was then added and samples were incubated for $10 \mathrm{~min}$ at $37^{\circ} \mathrm{C}$ prior to recording the absorbance at $540 \mathrm{~nm}$ according to manufacturers' protocol.

To test proliferation, $100 \mu \mathrm{l}$ of SDS-HCl solution was added to all wells with MTT and samples were incubated for $18 \mathrm{~h}$ at $37^{\circ} \mathrm{C}$. Viability was accepted as $100 \%$ prior to administration of the naproxen agent to cultures.

SSEA-1 chondrocyte activity assays. The SSEA-1 protein is upregulated during the differentiation of human mesenchymal stem cells containing embryonic stem cells; but downregulated in cells not undergoing differentiation $(1,9,12)$. The SSEA-1 Human Mesenchymal Stem Cell Characterization kit was used to classify cells in chondrocyte cultures as differentiating, not differentiating, stimulated or inhibited by determining whether SSEA-1 increases or decreases in all experimental groups.

Statistical analyses. Data are presented as the mean \pm standard deviation. Minitab R16 (version 16; Minitab, Inc., State College, PA, USA) was used for statistical evaluation and evaluations were performed at a $95 \%$ confidence interval. Analysis of variance was used to determine significant differences across groups, followed by Tukey's honest significant difference (HSD) to determine differences and investigate false positives. $\mathrm{P}<0.01$ was considered to indicate a statistically significant difference.

\section{Results}

Evaluation of inverted light microscopy and ESEM. The current study demonstrated that with increasing naproxen dose, cell morphology changed (Fig. 1). Cells lost specific shapes and appeared rounded as a reaction to naproxen treatment. These findings were confirmed by ESEM analyses. It was observed that chondrocytes lost their isogenous structures, 


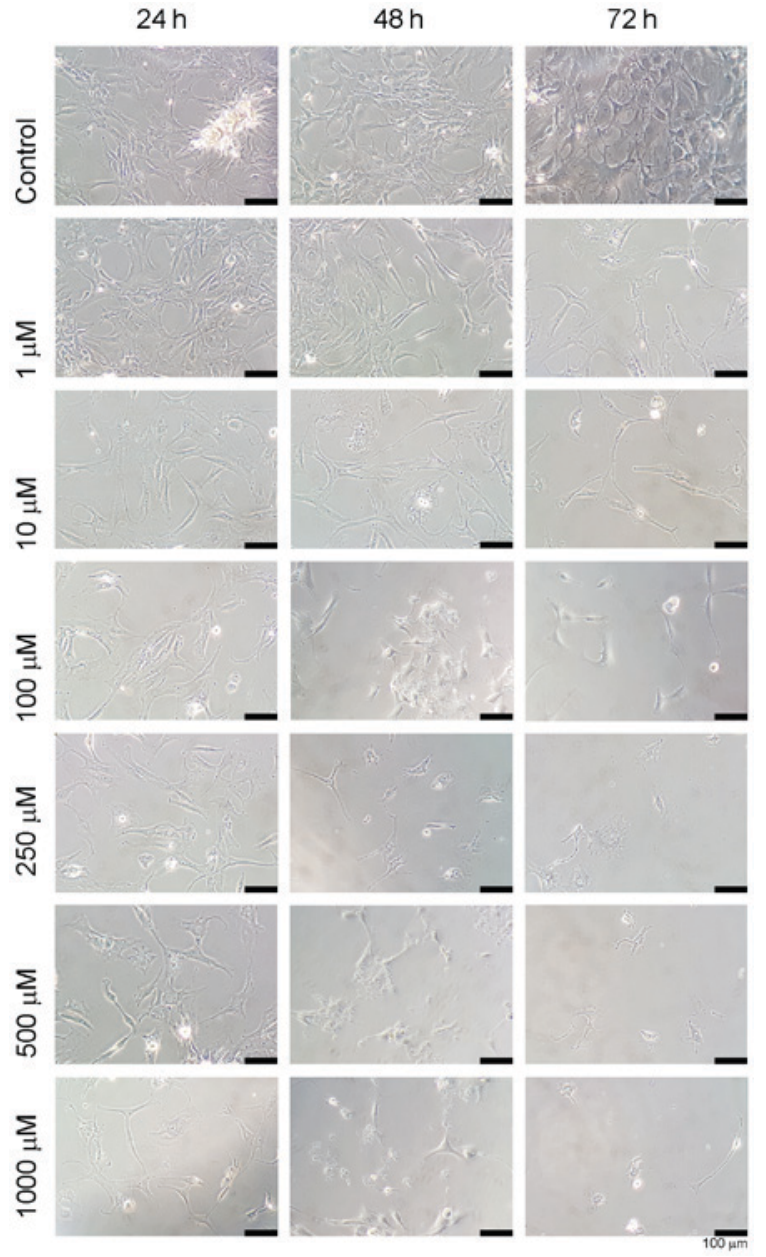

Figure 1. Evaluating cytotoxicity of naproxen using inverted light microscopy. The cells of the control group and the ECM were normal and proliferative. In addition, in all the control groups, the percentage of confluency following 24 and $72 \mathrm{~h}$ was $\sim 95 \%$. However, drug-treated groups exhibited a rounded shape from the 24th to the 72nd hour, particularly at concentrations of and above $100 \mathrm{mM}$ Naproxen. Moreover, ECM structures disappeared, and the group treated with $1,000 \mathrm{mM}$ naproxen almost entirely disappeared following $72 \mathrm{~h}$. Following $48 \mathrm{~h}$ in groups treated with and above $500 \mathrm{nM}$ naproxen, the confluence of cells decreased and proliferation was clearly visible. Scale bars, $100 \mu \mathrm{M}$.

crimped and disintegrated into ECM (Fig. 2). The number of cells with deteriorated morphology were primarily observed following the 72-h analysis of groups treated with $1,000 \mathrm{mM}$ naproxen.

MTT-ELISA and SSEA-1 analyses. Naproxen was revealed to suppress cell proliferation and differentiation and demonstrated a significant chondrotoxic effect $(\mathrm{P}<0.01$; Table II). The visual toxicity images produced via ESEM and inverted light microscopy supported the MTT results. As a result of this analysis, proliferation was demonstrated to be suppressed by increasing naproxen dose (Fig. 3; Tables II and III). It was observed that longer treatment $(\mathrm{P}=0.537)$ exerted greater effects on cell differentiation than higher doses $(\mathrm{P}=0.143)$.

Here the naproxen used by the patients will accumulate in the synovial fluid and reach the cartilage tissue. Although it does not kill the cells, it suppresses proliferation in the cartilage with slow proliferation and prolongs the healing process of the patients.

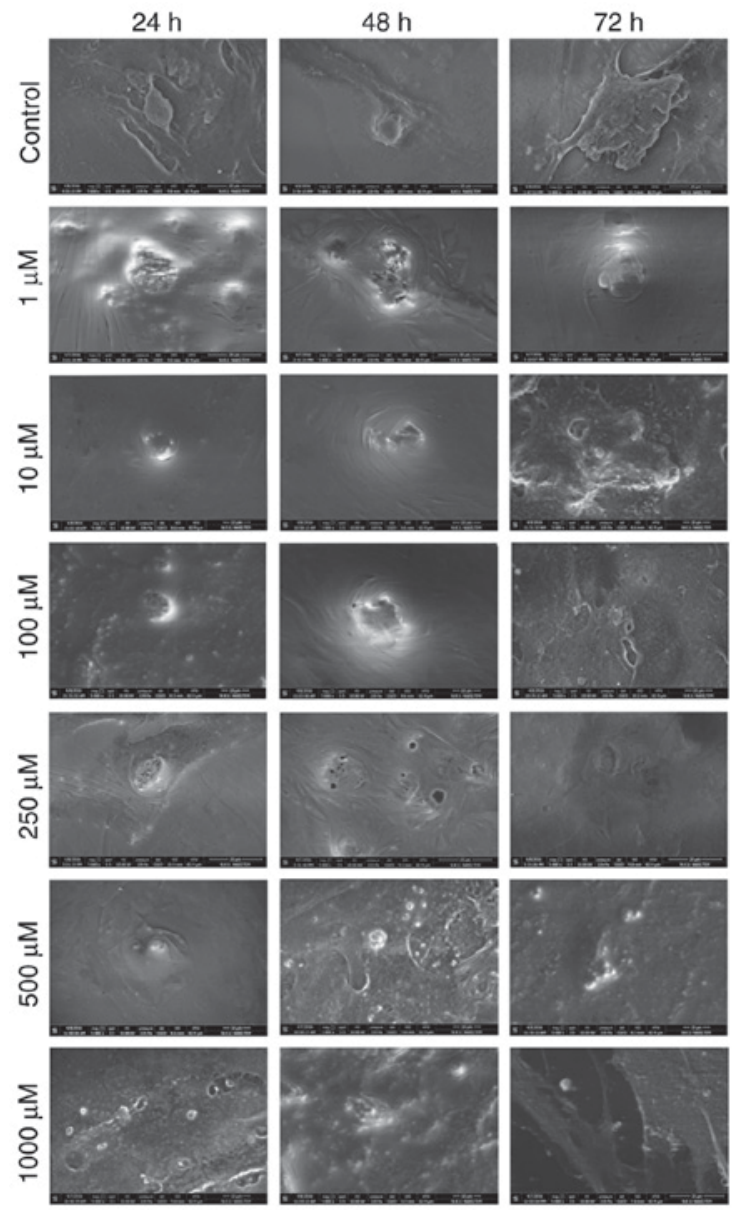

Figure 2. Evaluating surface morphology of chondrocytes using environmental scanning microscopy. All images were recorded at 219-226 Pa, with a magnification of $x 5,000$ and a resolution depth horizontal field width of $82.9 \mu \mathrm{m}$. The operating voltage was $5.00 \mathrm{kV}$ and the working distance was 7.3-10.3 mm. Healthy cells were observed following 24, 48 and $72 \mathrm{~h}$ in the control group. It was demonstrated that the samples in the groups treated with $1 \mu \mathrm{M}$ naproxen $(24,48$, and $72 \mathrm{~h})$ and $10 \mu \mathrm{M}(24$ and $48 \mathrm{~h})$ concentrations exhibited similar, healthy images to the control group. However, typical healthy histological images of chondrocytes were dulled or not observed in samples treated with $10 \mu \mathrm{M}$ following $72 \mathrm{~h}$. Samples that received 100, 250, 500 and $1,000 \mu \mathrm{M}$ naproxen (at 24, 48 and $72 \mathrm{~h}$ ) exhibited unhealthy and dulled images when compared with the control group. It was also observed at $72 \mathrm{~h}$ that the structure and integrity of the extracellular matrix had deteriorated and ruptured in some regions of the unhealthy chondrocytes, particularly in those treated with $1,000 \mu \mathrm{M}$ naproxen.

\section{Discussion}

Articular cartilage does not contain nerves, veins or lymphatic tissues. Therefore, cartilage cells, which are the articular surfaces of bones, are fed by a perichondrium layer in the vascular structure or by synovial fluid that washes the articular surface when there is no perichondrium $(10,13,18)$. Cartilage is also fed by a double diffusion system $(10,13,18)$. Since the outer layer of synovial fluid is thick, nutrition or drugs are diffused from synovial tissue to synovial fluid and thereafter pass from the synovial fluid through pores (6-8 $\mathrm{nm}$ long) in the cartilage structure prior to reaching chondrocytes, where diffusion occurs again $(13,18-20)$. In addition to the diffusion system, an active transport and intermittent loading pump system are of great importance in feeding of cartilage tissue (10,13,18-22). Any drug administered to the body accumulates in almost all tissues, including synovial 
Table II. Analysis of variance results for MTT and SSEA-1 assay data on naproxen treatment at vrying concentrations over time.

A, MTT-proliferation assay

\begin{tabular}{lcccrr}
\hline Source & DF & Adj SS & Adj MS & F-value & P-value \\
\hline Hour & 2 & 0.002 & 0.001 & 1.98 & 0.143 \\
Control & 1 & 0.176 & 0.176 & 479.44 & $<0.001$ \\
Dose & 5 & 0.002 & 0.000 & 0.82 & 0.537 \\
\hline
\end{tabular}

B, SSEA-1 differentiation assay

\begin{tabular}{lcccrr}
\hline Source & DF & Adj SS & Adj MS & F-value & P-value \\
\hline Hour & 2 & 0.062 & 0.031 & 15.96 & 0.000 \\
Control & 1 & 0.309 & 0.309 & 159.93 & 0.000 \\
Dose & 5 & 0.001 & 0.000 & 0.12 & 0.987 \\
\hline
\end{tabular}

DF, degrees of freedom; Adj SS, adjusted sum of squares; Adj MS, adjusted mean square; SSEA-1, stage-specific embryonic antigen-1.

Table III. Statistical analyses of pairwise comparisons for SSEA-1 protein and MTT-cell proliferation assays, with grouping information using Tukey's test at $95 \%$ confidence interval.

A, MTT-cell viability, toxicity and proliferation assay

\begin{tabular}{lc}
\hline Hour & Absorbance (OD) \\
\hline Control 24 & 0.369 \\
Control 48 & 0.367 \\
Control 72 & 0.406 \\
Naproxen 24 & 0.362 \\
Naproxen 48 & 0.325 \\
Naproxen 72 & 0.325 \\
\hline
\end{tabular}

B, Stage-specific embryonic antigen-1 assay

\begin{tabular}{lc}
\hline Hour & Absorbance (OD) \\
\hline Control 24 & 0.462 \\
Control 48 & 0.472 \\
Control 72 & 0.504 \\
Naproxen 24 & 0.442 \\
Naproxen 48 & 0.411 \\
Naproxen 72 & 0.397 \\
\hline
\end{tabular}

OD optical density.

tissue. NSAIDs pass through the synovial fluid compartment very slowly. However, NSAIDs penetrate the plasma membrane and accumulate with fluctuations over time (23-27). Numerous developments that have taken place in pharmaceutical and regenerative medicine and various studies have focused on ways to protect and repair tissue damage and on the toxicity of treatments at a molecular level $(10,13,19)$. Orthopedic or neurosurgeons are interested in repairing tissue damage using biological methods $(19,20,28)$. Previous studies have evaluated protecting and repairing tissue damage, particularly in articular cartilage, while others have examined effects of drugs on healthy cartilage, facet joint and bone tissue $(10,13,19,20,28)$.

The present study examined effects of naproxen, a widely prescribed aryl acetic acid derivative, at a molecular level. Effects on human articular primary cartilage cells were studied and a toxic effect, in many cases involving painful and inflammatory musculoskeletal diseases (29), was evaluated. The current study, combined with a previous study considered the effect of naproxen alone and in combination with other NSAIDs following major surgery and minimally invasive surgeries, including arthroscopy and spine surgery, respectively (29).

Cytotoxicity research has included experimentation using tissues obtained from animals (30). However, results are not transferable to human studies because of differences in physiological structure and sensitivity $(15,16)$. Another study was performed with commercial cell lines rather than animal tissues (31). However, as these lines do not contain microenvironments, including ECM, and only represent one type cell, they are known to lose their original phenotypic and genotypic characteristics $(1,10,13,15,16,18-20)$. The current study did not utilize animal tissue or commercial cell lines to examine effects of naproxen on chondrocytes. Instead, cartilage tissues from patients who had received knee prostheses in the course of routine clinical practice were obtained. As primary cultures taken from the chondral materials derived from the lateral compartment, analyses of environments, including ECM were performed in addition to investigation of cartilage cells. ECM formation in cultures was examined morphologically through an inverted light microscope and ESEM.

The possibility that patients were administered drugs prior to this study, which may have accumulated in synovial tissue and passed through cartilage tissue, was taken into consideration. Acidic drug molecules that may have accumulated in tissues may interact with naproxen, thereby causing toxicity (13). For this reason, patient histories were evaluated and patients with prior NSAIDs, disease-modifying antirheumatic drug and biological agent treatment were excluded.

Cheleschi et al (32) reported that the cyclooxigenase2-inhibiting hybrid drug VA694, which enables nitric oxide, exhibited anti-inflammatory and antinociceptive features. The authors further studied the protective effects of VA694 in comparison with naproxcinod and naproxen on cartilage tissue. Two concentrations (1 and $10 \mu \mathrm{M})$ were analyzed. Immunohistochemistry was performed to analyze chondrocytes and nuclear factor $\kappa$ B. It was demonstrated that VA694 was not sufficient to promote cell viability, although interleukin (IL) $-1 \beta$ had a negative effect, causing a significant decrease in VA694. Furthermore, it was reported that concentrations used in VA694 were effective in preserving IL-1 $\beta$-stimulated chondrocytes (32). It was demonstrated that Naproxen did not exert any protective or positive contribution to chondrocytes and/or ECM; however, no side effects were mentioned in the present study. We expressed our results because it was said to have protective efficacy as much as naproxen and naproxcinod. 

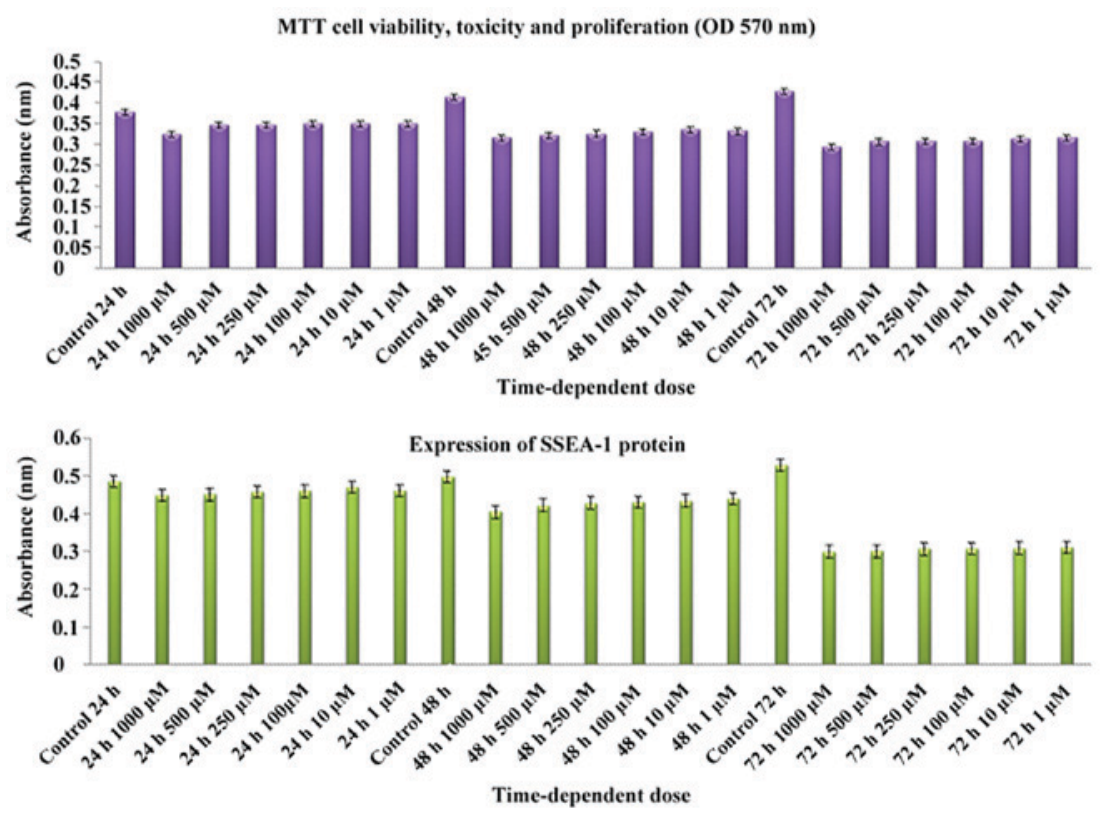

Figure 3. Changes in SSEA-1 protein levels and MTT assay results providing information on cell viability, toxicity and proliferation.

But naproxen does not have protective effect on the mentioned tissue However; we found that chondrocyte proliferation and SSEA-1 expression decreased in naproxen 72th hour's administration in our study.

Previous aforementioned research has indicated that naproxen gives rise to chondrocyte hypertrophy. However, the present study determined that proliferation was suppressed. These differences may be due to the addition of dexamethasone into the medium utilized in previous studies. This negative effect, which was observed, may have therefore been due to the coexistence of the two chemicals. Dexamethasone was added to the medium used for culturing. It has been reported that dexamethasone does not account for increases in chondrogenic activity but may increase osteogenic activity (33). In addition, dexamethasone is a pharmacological agent that has been used to suppress inflammation (34). Certain previous studies added dexamethasone to the medium when preparing cultures; however, it is important to ensure that dexamethasone is not added to cultural environments, as it may suppress chondrocyte proliferation $(35,36)$.

The current study used molecular methods and microscopy to demonstrate that naproxen suppressed chondrocyte viability and proliferation and suppressed prechondrocytic precursor cell differentiation into mature chondrocytes in primary human chondrocyte cultures. Images of cells with rounded shapes were observed and the poor development of ECM was also visualized. The present study hypothesized that that naproxen suppressed the development of cytotoxic and ECM structures. The current study, which examined a broad concentration range of naproxen (doses of 1-1,000 $\mu \mathrm{M}$ ), demonstrated all concentrations stopped cell proliferation following $72 \mathrm{~h}$ treatment, and SSEA-1 protein levels were decreased. As SSEA-1 is a marker for chondrocytic differentiation (13), no further morphological experiments, including flow cytometry or Giemsa staining were performed. Previous studies have also demonstrated that ESEM analysis reveals morphological abberations $(10,13,37)$.
Recorded inverted light microscopy images demonstrate naproxen toxicity and repression of cell proliferation. Morphological changes occurring during proliferation were confirmed by ESEM. As naproxen was demonstrated to suppress cellular proliferation, it was further linked to a decrease in SSEA-1 level. In the present study, varying concentrations of naproxen $(1-1,000 \mu \mathrm{M})$ were evaluated at varying treatment lengths and chondrotoxic effects were demonstrated via suppressed proliferation and differentiation of chondrocytes.

Using inverted light microscopy and ESEM, it was observed that as the dose increased, cell morphology changed, with cells losing their specific shapes and becoming rounded, as a reaction to cytotoxic agents. Using MTT and SSEA-1 assays however, it was demonstrated that longer durations exerted greater effects on cell viability compared with higher doses.

In conclusion the present study evaluated effects of naproxen, an aryl acetic acid derivative drug, on cell viability of cartilage tissues using human primary chondrocyte cultures. Although data obtained from in vitro experiments does not directly compare to clinical practice, it may guide understanding of how a drug prescribed for symptomatic relief of another disease suppresses chondrocyte cell proliferation and chondrogenic differentiation.

\section{Acknowledgements}

Not applicable.

\section{Funding}

No funding was received.

\section{Availability of data and materials}

The datasets used and/or analyzed during the current study are available from the corresponding author on reasonable request. 


\section{Authors' contributions}

NKar and AGB conceived and designed the present study. NKar also acquired subjects and data, and analyzed/interpreted the data; AGB diagnosed and operated on patients and removed tissues. IY prepared the human primer chondrocyte culture, performed inverted light microscopy, conducted/analyzed ELISA and prepared/stored culture drugs. IY and HO prepared drugs and adapted clinical doses to cell cultures, performed statistical analyses and wrote the manuscript. TC selected the patients who met the inclusion criteria and acquired subjects and data. DYS prepared the human primer chondrocyte culture and performed/analyzed PCR. NKap and OA transferred tissues to the laboratory and acquired subjects and data. KO diagnosed and operated on patients and removed tissues. NKar, DYS, NKap, KO, HO and OA contributed to the preparation and critical revision of the manuscript. All authors have read and approved the final version of the manuscript.

\section{Ethics approval and consent to participate}

This scientific research project was undertaken with the approval of the Ethics Committee of the Istanbul Medipol University School of Medicine, Istanbul, Turkey (10840098-604.01.01-E.5734). Signed consent forms were obtained from all patients.

\section{Patient consent for publication}

Not applicable.

\section{Competing interests}

The authors declare that they have no competing interests.

\section{References}

1. Isyar M, Yilmaz I, Yasar Sirin D, Yalcin S, Guler O and Mahirogullari M: A practical way to prepare primer human chondrocyte culture. J Orthop 13: 162-167, 2016.

2. Gökçe A, Yılmaz I, Gökay NS, Can L and Gökçe C: Does insulin, transferrin and selenous acid preparation effect chondrocyte proliferation? Acta Orthop Traumatol Turc 48: 313-319, 2014

3. Sugimoto M, Toda Y, Hori M, Mitani A, Ichihara T, Sekine S, Hirose T, Endo H, Futaki N, Kaku S, et al: Analgesic effect of the newly developed $\mathrm{S}(+)$-flurbiprofen plaster on inflammatory pain in a rat adjuvant-induced arthritis model. Drug Dev Res 77: $20-28,2016$.

4. Dragoo JL, Korotkova T, Kim HJ and Jagadish A: Chondrotoxicity of low $\mathrm{pH}$, epinephrine, and preservatives found in local anesthetics containing epinephrine. Am J Sports Med 38 1154-1159, 2010.

5. Prevette LE, Benish NC, Schoenecker AR and Braden KJ: Cell-penetrating compounds preferentially bind glycosaminoglycans over plasma membrane lipids in a charge density- and stereochemistry-dependent manner. Biophys Chem 207: 40-50, 2015.

6. Shahin MH and Johnson JA: Mechanisms and pharmacogenetic signals underlying thiazide diuretics blood pressure response. Curr Opin Pharmacol 27: 31-37, 2016.

7. Van Hecken A, Schwartz JI, Depré M, De Lepeleire I, Dallob A, Tanaka W, Wynants K, Buntinx A, Arnout J, Wong PH, et al: Comparative inhibitory activity of rofecoxib, meloxicam, diclofenac, ibuprofen, and naproxen on COX-2 versus COX-1 in healthy volunteers. J Clin Pharmacol 40: 1109-1120, 2000.

8. Al Khaja KAJ, Veeramuthu S, Isa HA and Sequeira RP: Prescription audit of NSAIDs and gastroprotective strategy in elderly in primary care. Int J Risk Saf Med 29: 57-68, 2017.
9. Ruschitzka F, Borer JS, Krum H, Flammer AJ, Yeomans ND, Libby P, Lüscher TF, Solomon DH, Husni ME, Graham DY, et al: Differential blood pressure effects of ibuprofen, naproxen, and celecoxib in patients with arthritis: The PRECISION-ABPM (Prospective Randomized Evaluation of Celecoxib Integrated Safety Versus Ibuprofen or Naproxen Ambulatory Blood Pressure Measurement) trial. Eur Heart J 38: 3282-3292, 2017.

10. Gumustas SA, Yilmaz İ, Isyar M, Sirin DY, Batmaz AG, Ugras AA, Oznam K, Ciftci Z and Mahirogullari M: Assessing the negative impact of phenyl alkanoic acid derivative, a frequently prescribed drug for the suppression of pain and inflammation, on the differentiation and proliferation of chondrocytes. J Orthop Surg Res 11: 70, 2016.

11. Aw TJ, Haas SJ, Liew D and Krum H: Meta-analysis of cyclooxygenase-2 inhibitors and their effects on blood pressure. Arch Intern Med 165: 490-496, 2005.

12. Lee JL, Mukhtar H, Bickers DR, Kopelovich L and Athar M: Cyclooxygenases in the skin: Pharmacological and toxicological implications. Toxicol Appl Pharm 192: 294-306, 2013.

13. Oznam K, Sirin DY, Yilmaz I, Kaya YE, Isyar M, Gumustas SA Ozbek H, Akkaya S, Kayhan A and Mahirogullari M: Iopromide-and gadopentetic acid-derived preparates used in MR arthrography may be harmful to chondrocytes. J Orthop Surg Res 12: 98, 2017.

14. Kellgren JH and Lawrence JS: Radiological assessment of osteo-arthritis. Ann Rheum Dis 16: 494-502, 1957.

15. Guzelant AY, Isyar M, Yilmaz I, Sirin DY, Cakmak S and Mahirogullari M: Are chondrocytes damaged when rheumatologic inflammation is suppressed? Drug Chem Toxicol 40: 13-23, 2017.

16. Isyar M, Bilir B, Yilmaz I, Cakmak S, Sirin DY, Guzelant AY and Mahirogullari M: Are biological agents toxic to human chondrocytes and osteocytes? J Orthop Surg Res 10: 118, 2015.

17. Isyar M, Yilmaz I, Nusran G, Guler O, Yalcin S and Mahirogullari M: Safety of bioabsorbable implants in vitro. BMC Surg 15: 127, 2015.

18. Sirin DY, Kaplan N, Yilmaz I, Karaarslan N, Ozbek H, Akyuva N, Kaya YE, Oznam K, Akkaya N, Guler O, et al: Investigation of the relationship between different molecular weight hyaluronic acid applications and CHAD, HIF1 $\alpha$, COL2A1 expression in chondrocyte cultures. Exp Ther Med, 2017.

19. Karaarslan N, Yilmaz I, Isyar M, Ozbek H, Akyuva Y, Sirin DY, Gurbuz MS, Caliskan T, Kaplan N, Kaya YE, et al: Do nitric oxide synthases enzyme inhibitors affect chondrocyte activity? Merit Res J Med Med Sci 5: 635-645, 2017.

20. Sirin DY and Karaarslan N: Evaluation of the effects of pregabalin on chondrocyte proliferation and CHAD, HIF-1 $\alpha$, and COL2A1 gene expression. Arch Med Sci, 2018. DOI: https://doi. org/10.5114/aoms.2018.73134.

21. Sterner B, Harms M, Wöll S, Weigandt M, Windbergs M and Lehr CM: The effect of polymer size and charge of molecules on permeation through synovial membrane and accumulation in hyaline articular cartilage. Eur J Pharm Biopharm 101: 126-136, 2016.

22. Villalvilla A, Gómez R, Largo R and Herrero-Beaumont G: Lipid transport and metabolism in healthy and osteoarthritic cartilage. Int J Mol Sci 14: 20793-20808, 2013

23. Brooks PM: NSAIDs. In: Textbook of rheumatology. Klippel JH (Eds), Dieppe PA. 2nd ed. Harcourt Publisher Ltd. London, pp1-6, 2000.

24. Brambilla G, Civitareale C, Pierdominici E, De Giovanni F and Anastasio A: Synovial fluid as a matrix of selection in the detection of beta-adrenergic agonist drugs in carcasses and fresh meat. Analyst 119: 2591-2593, 1994.

25. Tang H, Yan M, Li H, Xun T, Deng Y, Zhao Y and Deng L: Dynamic detection of non-protein-bound strychnine and brucine in rabbit muscle and synovial fluid after topical application of total Strychnos alkaloid patches. Drug Test Anal 6: 357-362, 2014

26. Yataba I, Otsuka N, Matsushita I, Kamezawa M, Yamada I, Sasaki S, Uebaba K, Matsumoto H and Hoshino Y: Plasma pharmacokinetics and synovial concentrations of S-flurbiprofen plaster in humans. Eur J Clin Pharmacol 72: 53-59, 2016.

27. Zacharowski P, Breese E, Wood E, Del Soldato P, Warner T and Mitchell J: NSAIDs increase GM-CSF release by human synoviocytes: Comparison with nitric oxide-donating derivatives. Eur J Pharmacol 508: 7-13, 2005.

28. Karaarslan N, Yilmaz I, Ozbek H, Sirin DY, Kaplan N, Akyuva Y, Gonultas A and Ozkan A: Are specific gene expressions of extracellular matrix and nucleus pulposus affected by primer cell cultures prepared from intact or degenerative intervertebral disc tissues? Turk Neurosurg, 2018. 
29. van Leeuwen JS, Unlü B, Vermeulen NP and Vos JC: Differential involvement of mitochondrial dysfunction, cytochrome P450 activity, and active transport in the toxicity of structurally related NSAIDs. Toxicol In Vitro 26: 197-205, 2012.

30. Di Salvo A, Chiaradia E, della Rocca G, Mancini F, Galarini R, Giusepponi D, De Monte V, Cagnardi P, Marenzoni ML and Bufalari A: Intra-articular administration of lidocaine plus adrenaline in dogs: Pharmacokinetic profile and evaluation of toxicity in vivo and in vitro. Vet J 208: 70-75, 2016.

31. Stueber T, Karsten J, Stoetzer C and Leffler A: Differential cytotoxic properties of drugs used for intra-articular injection on human chondrocytes: An experimental in-vitro study. Eur J Anaesthesiol 31: 640-645, 2014.

32. Cheleschi S, Pascarelli NA, Valacchi G, Di Capua A, Biava M, Belmonte G, Giordani A, Sticozzi C, Anzini M and Fioravanti A Chondroprotective effect of three different classes of anti-inflammatory agents on human osteoarthritic chondrocytes exposed to IL-1 $\beta$. Int Immunopharmacol 28: 794-801, 2015.

33. Bae S, Lee HJ, Lee JS and Webb K: Cell-mediated dexamethasone release from semi-IPNs stimulates osteogenic differentiation of encapsulated mesenchymal stem cells. Biomacromolecules 16 : $2757-2765,2015$
34. Utomo L, van Osch GJ, Bayon Y, Verhaar JA and Bastiaansen-Jenniskens YM: Guiding synovial inflammation by macrophage phenotype modulation: An in vitro study towards a therapy for osteoarthritis. Osteoarthritis Cartilage 24: 1629-1638, 2016.

35. Wernecke C, Braun HJ and Dragoo JL: The effect of intra-articular corticosteroids on articular cartilage: A systematic review. Orthop J Sports Med 3: 2325967115581163, 2015.

36. Wyles CC, Houdek MT, Wyles SP, Wagner ER, Behfar A and Sierra RJ: Differential cytotoxicity of corticosteroids on human mesenchymal stem cells. Clin Orthop Relat Res 473: 1155-1164, 2015.

37. Yaşar Sirin D, Yılmaz İ, İşyar M, Öznam K and Mahiroğulları M: Does leukocyte-poor or leukocyte-rich platelet-rich plasma applied with biopolymers have superiority to conventional platelet-rich plasma applications on chondrocyte proliferation? Eklem Hastalik Cerrahisi 28: 142-151, 2017.

(7)(9) This work is licensed under a Creative Common EY No No Attribution-NonCommercial-NoDerivatives 4.0 International (CC BY-NC-ND 4.0) License. 